\title{
The P34 Syringolide Elicitor Receptor Interacts with a Soybean Photorespiration Enzyme, NADH-Dependent Hydroxypyruvate Reductase
}

\author{
Yasushi Okinaka, ${ }^{1}$ Ching-Hong Yang, ${ }^{1}$ Eliot Herman, ${ }^{2}$ Anthony Kinney, ${ }^{3}$ and Noel T. Keen ${ }^{1}$ \\ ${ }^{1}$ Department of Plant Pathology and Center for Plant Cell Biology, University of California, Riverside 92521 U.S.A.; \\ ${ }^{2}$ Plant Genetics Unit, USDA-ARS Donald Danforth Plant Science Center, 975 N. Warson Rd., St. Louis, MO 63132 U.S.A.; \\ ${ }^{3}$ Dupont Experimental Station, Rt. 141 and Henry Clay Road, Wilmington, DE 19880 U.S.A.
}

Submitted 6 May 2002. Accepted 6 August 2002.

\begin{abstract}
The syringolide receptor P34 mediates avrD-Rpg4 gene-forgene complementarity in soybean. However, the mechanism underlying P34 signal transmission after syringolide binding is unknown. In an effort to identify a second messenger for P34, soybean leaf proteins were run though a P34-affinity column. A 42-kDa protein which specifically bound to the column was identified as a putative plant NADH-dependent hydroxypyruvate reductase (HPR) by $\mathrm{N}$-terminal peptide sequencing. HPR is an important enzyme involved in the plant photorespiration system. Screening of a soybean cDNA library yielded two distinct HPR clones that encoded proteins with $97 \%$ identity (P42-1 and P42-2). Surprisingly, only P422 displayed good binding with P34 in a yeast two-hybrid assay, indicating that $\mathbf{P 4 2 - 2}$, but not $\mathbf{P 4 2}-1$, is a potential second messenger for P34. Glycerate and its analogs, which are utilized in the photorespiration system, were tested for their inhibitory effect on syringolide-induced hypersensitive response (HR) to evaluate the biological significance of P42-2. Interestingly, the downstream products of HPR (glycerate and 3-phosphoglycerate) inhibited HR but the upstream compounds (hydroxypyruvate or serine) did not have a significant effect on HR. These results suggest that P42-2 is a primary target for a P34/syringolide complex and that P42-2 binding with the complex probably induces HR by inhibiting one or more HPR functions in soybean.
\end{abstract}

Syringolides are water-soluble, low-molecular-weight elicitors produced in Escherichia coli or several other gram-negative bacteria expressing avirulence gene $D(a v r D)$ (Midland et al. 1993; Yucel et al. 1994). avrD originally was cloned from Pseudomonas syringae pv. tomato (Kobayashi et al. 1990) and occurs in several $P$. syringae isolates. The purified syringolides or bacteria expressing $a v r D$ elicit the hypersensitive response (HR) specifically in soybean cultivars carrying the Rpg4 disease resistance gene (Keen and Buzzell 1991; Keen et al. 1990). Therefore, syringolides mediate the avrD-Rpg4 gene-for-gene complementarity system (Flor 1971) in soybean. The syringolide elicitors are at least 1,000 times more active in Rpg4 than in rpg4 cultivars. It is possible that this specificity is determined at the level of a primary syringolide binding site (receptor).

Corresponding author: Yasushi Okinaka, Telephone: 909-787-4134; Fax: 909-787-4294; E-mail:okinakayas@aol.com

Data deposition: The cDNA and amino acid sequences of P42-1 and P422 have been submitted to the GenBank database (accession no. AF503360 and AF503361, respectively).
Based on this presumption, we synthesized radiolabeled syringolide 1 as well as several syringolide derivatives with altered biological activities and demonstrated that the soluble fractions of extracts from both Rpg4 and rpg4 soybean leaves contain one or more ligand-specific, saturable binding sites for the syringolide elicitor (Ji et al. 1997). The one or more observed syringolide binding sites showed high ligand selectivity and a strong correlation was observed between competitive binding activity and elicitor activity for all compounds tested. Therefore, one or more identified binding sites is a candidate for the physiologically active syringolide receptor. In order to isolate the putative syringolide receptor, we prepared a syringolide affinity-gel column and fractionated proteins with syringolide 1 binding activity. The syringolide binding protein was revealed to be a $34-\mathrm{kDa}$ protein identical to $\mathrm{P} 34$, a previously described soybean seed allergen (Ji et al. 1998; Kalinski et al. 1990; Ogawa et al. 1991, 1993).

P34 is a moderately abundant protein in soybean seeds and cotyledons but its level in mature leaves is low (Kalinski et al. 1992). In soybean seeds, P34 is processed from a 46-kDa precursor protein and was shown to have homology with thiol proteases. P34, but not the 46-kDa precursor protein, exhibited ligand-specific syringolide binding activity, indicating that P34 may be the receptor that mediates syringolide signaling ( $\mathrm{Ji}$ et al. 1998). P34 does not share characteristics with previously described disease resistance genes such as a leucine-rich repeat, nucleotide binding site, toll/interleukin-1 receptor-like domain, leucine zipper, or protein kinase domain (Wilson and Somerville 2000). Although P34 has a thiol-protease-like structure, protease activity in P34 has not been demonstrated. Thus, the mechanism by which P34 transmits the syringolidebinding signal to a putative second messenger to invoke resistance responses is unknown. One approach to address the P34mediated signaling mechanism is by isolation of P34 binding factors in soybean. In this study, we report isolation and characterization of a putative second messenger for P34 and also suggest its possible role in HR induction in soybean.

\section{RESULTS}

\section{Column chromatography.}

Soluble protein fractions were prepared from Rpg4 soybean (cv. Harosoy) leaves and applied onto a P34-bound affinity resin column to identify proteins that interact with the P34 syringolide elicitor receptor. Soybean proteins remaining after column washing were eluted with a 0-to-1-M NaCl linear gradient and fractionated. A $42-\mathrm{kDa}$ protein (P42) was specifi- 
cally observed in some fractions eluted from P34-bound resin compared with the control experiment using the resin without P34 ligand (Fig. 1). The fractions containing P42 were collected and further fractionated by ion-exchange chromatography (Fig. 2). P42-enriched protein samples (Fig. 2, fraction no. 11) were separated by $12 \%$ sodium dodecyl sulfate-polyacrylamide gel electrophoresis (SDS-PAGE), transferred onto a polyvinilidene difluoride (PVDF) membrane, and used for N-terminal amino acid sequencing. As a result, $10 \mathrm{~N}$-terminal amino acids (AKPVSIEVWN) were repeatedly obtained and revealed to have significant homology with two NADH-dependent hydroxypyruvate reductases (HPRs) from an Arabidopsis sp. (BAA19751) and cucumber (P13443) by BLASTP search.

\section{Isolation of HPR clones.}

To isolate soybean HPR (P42) cDNA, two degenerate polymerase chain reaction (PCR) primers were designed according to the amino acid homology among given three HPRs (Fig. 3A). A PCR reaction using the two degenerate primers and Harosoy leaf cDNA as the template successfully amplified a single band with the expected size (approximately 400 bp) (Fig. 3B). DNA sequencing of the 400-bp fragment confirmed that the sequence was consistent with HPR. A Harosoy leaf cDNA library was screened by plaque hybridization using the 400-bp fragment as the probe for the isolation of full-length P42 cDNA clones. Among 74 positive signals out of 50,000 independent plaques
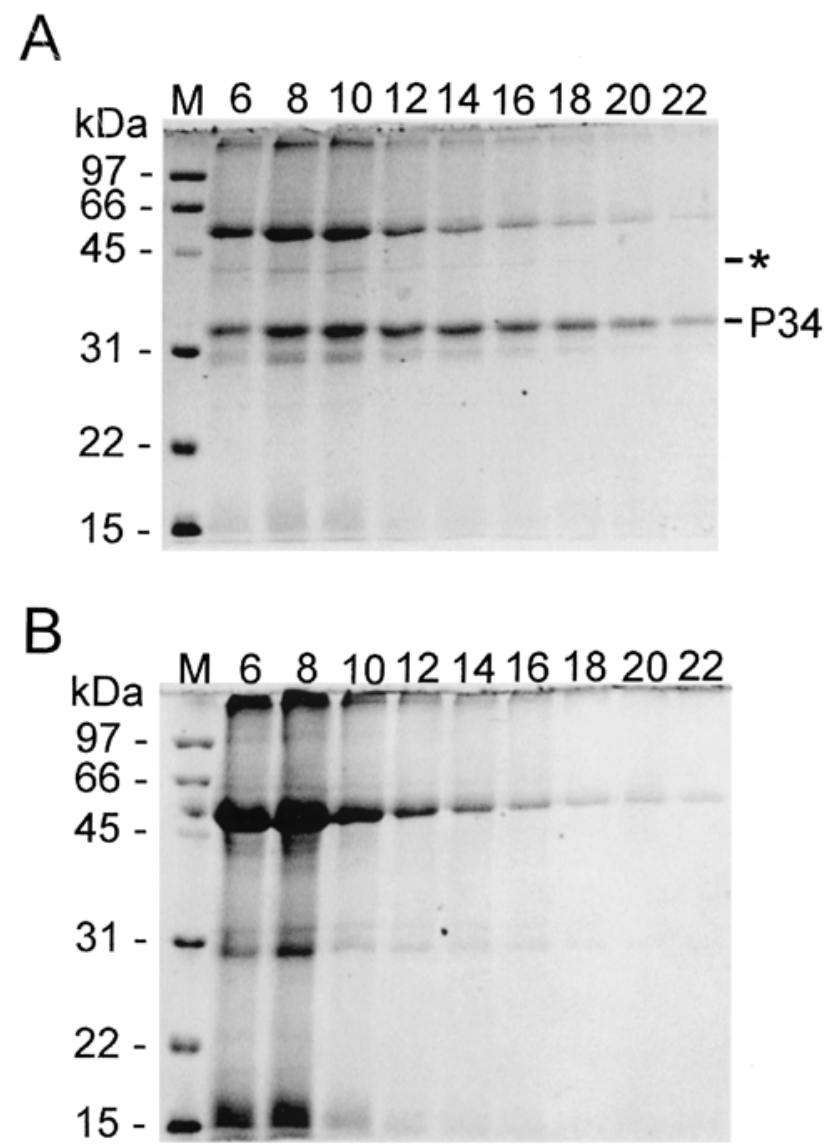

Fig. 1. Identification of a soybean leaf protein that binds with P34. Soluble protein fractions prepared from Harosoy leaves were run through the Affi-Gel15 gel A, linked to P34 or B, not linked to P34. After washing, the columns were eluted with a 0 -to-1-M NaCl linear gradient and eluted fractions (1 to 35) were collected. Resulting protein fractions then were separated by $12 \%$ sodium dodecyl sulfate-polyacrylamide gel electrophoresis and stained by Coomassie Brilliant Blue R-250. Fraction numbers are denoted on the top. The asterisk indicates a $42-\mathrm{kDa}$ unique protein. $\mathrm{M}$ $=$ protein size markers. screened, five clones were randomly chosen, physically mapped with restriction enzymes, and end sequenced. As a result, the five clones were sorted into two classes (data not shown). Complete sequencing of the two classes of cDNAs revealed that they encoded proteins with $97 \%$ amino acid homology to each other (Fig. 4). The two proteins were named P42-1 and P42-2, respectively. BLASTP search for P42-2 homologs against all GenBank sequences hit some plant HPRs. P42-2 shared strong homology with Arabidopsis spp. (89\%), pumpkin (88\%), cucumber (88\%), and mangrove $(91 \%)$ HPRs. Excluding these four plant HPRs, the highest homology score obtained was at most $36 \%$ with the lactate hydrogenase in Thermoanaerobacter tengcongensis. These results strongly indicate that both P42-1 and P42-2 are soybean HPRs. The C-terminal three contiguous amino acids, SKL, observed in both P42-1 and P42-2, are known as a peroxisome targeting signal (Gould et al. 1989).

\section{Binding assay using the yeast two-hybrid system.}

To determine whether both or either of the P42s bind P34, binding was evaluated using the yeast two-hybrid system. P34 was fused with the LexA DNA binding domain (BD) and coexpressed with $\mathrm{P} 42-1$ or $\mathrm{P} 42-2$ linked to the B42 acidic activator domain (AD). When the P42-1 fusion protein was co-expressed with the P34 construct in EGY48 yeast cells, only a trace of binding was detected between them (Fig. 5). In contrast, P42-2 and P34 co-expression in EGY48 cells showed good binding as evidenced by high $\beta$-galactosidase protein expression (Fig. 5). No $\beta$-galactosidase activity was obtained with P42-2 or P34 expression alone, supporting the specificity of P42-2/P34 binding. It is surprising that only P42-2 demonstrated binding activity with P34 even though $97 \%$ amino acid identity was observed between P42-1 and P42-2. This indicates that binding specificity is determined by 11 or fewer amino acids (Fig. 4). Accordingly, P42-2 is a primary candidate as a second messenger for the P34 syringolide receptor.

Effect of HPR-related substances on syringolide sensitivity.

HPR is an important enzyme involved in the plant photorespiration system (Fig. 6). HPR is known to be localized to plant peroxiomes and catalyze conversion of hydroxypyruvate to glycerate. Glycerate is then converted to 3-phosphoglycerate in plant chloroplasts and used as a substrate for the Calvin cycle. Glycerate was tested for its inhibitory effect on syringolideinduced HR to evaluate the possibility that HR is induced in

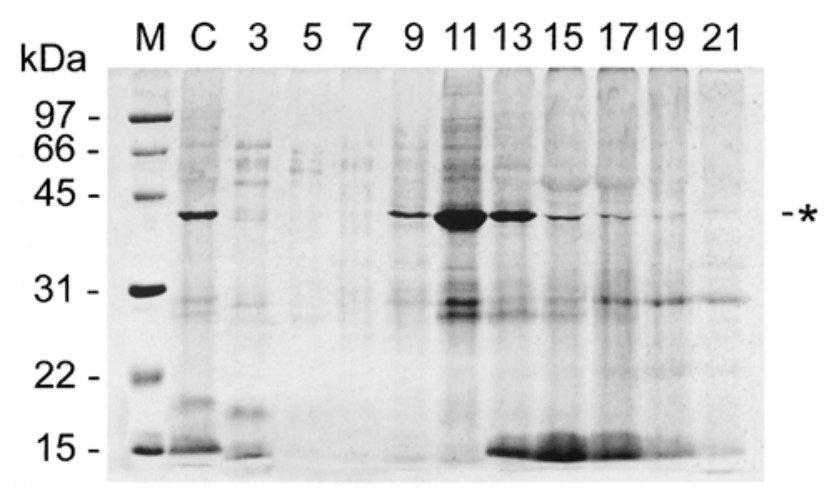

Fig. 2. Fractionation of the $42-\mathrm{kDa} \mathrm{P} 34$ binding protein by ion-exchange chromatography. Crude $42-\mathrm{kDa}$ proteins enriched by the affinity chromatography were run through a DEAE BIO-GEL A column. After washing, proteins on the column were eluted by a 0 -to- $0.4-\mathrm{M} \mathrm{NaCl}$ linear gradient and eluted fractions ( 1 to 26$)$ were collected. Fractionated proteins were separated by $12 \%$ sodium dodecyl sulfate-polyacrylamide gel electrophoresis and visualized by silver staining. Fraction numbers are denoted on the top. The asterisk indicates the $42-\mathrm{kDa}$ protein. $\mathrm{M}=$ protein size markers and $\mathrm{C}=$ the crude protein sample applied onto the column. 
soybean cells when P42-2 activity is inhibited by P34 together with syringolide. Interestingly, co-infiltration of $50 \mathrm{mM}$ glycerate with syringolide completely inhibited HR on soybean leaves (Table 1). Similarly, partial HR inhibition was obtained with 10 $\mathrm{mM}$ glycerate. 3-Phosphoglycerate also completely suppressed $\mathrm{HR}$ in a lower concentration (10 $\mathrm{mM})$ (Table 1). However, hydroxypyruvate did not significantly affect $\mathrm{HR}$ at $30 \mathrm{mM}$, though its molecular structure is similar to glycerate (Table 1; Fig. 6). A similar result was obtained by syringolide infiltration with 100 $\mathrm{mM}$ serine, which is just upstream of hydroxypyruvate and also structurally close to glycerate. These observations suggest that syringolide may inhibit P42-2 activity together with P34 and disturb the Calvin cycle-photorespiration cycle coordination, ultimately resulting in HR.
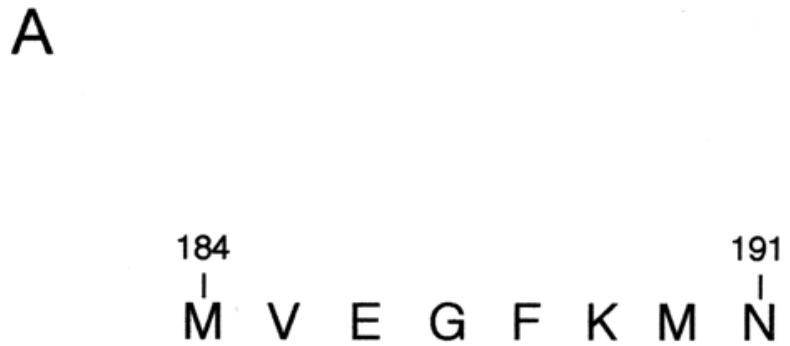

PR42F: 5'- ATG GTN GAR GGN TTY AAR ATG AA -3'

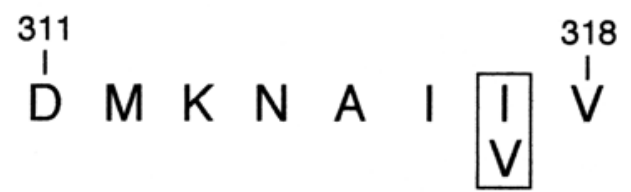

PR42R: 3'- CTR TAC TTY TTR CGN TAD YAN CA -5'

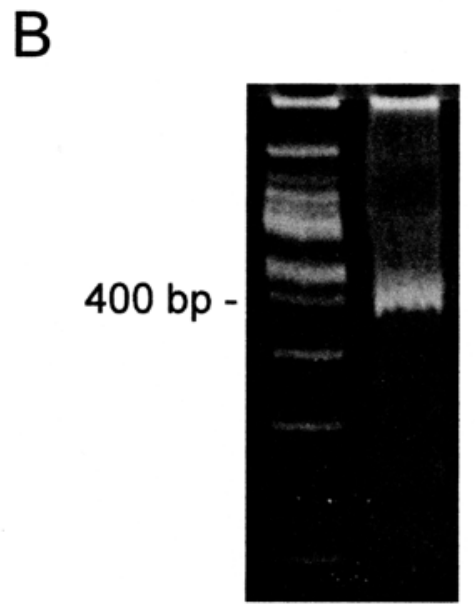

Fig. 3. Amplification of soybean hydroxypyruvate reductase (HPR) cDNA by degenerate primer polymerase chain reaction (PCR). A, The two amino acid sequences shown are completely conserved among three plant HPRs (Arabidopsis sp., BAA19751; pumpkin, S68164; cucumber, P13443), except one position surrounded by the square. To amplify soybean HPR cDNA, two degenerate primers, PR42F and PR42R, were designed according to the conserved HPR sequences. The numbers above the sequences denote amino acid positions in the three HPRs. B, PCR was performed using the degenerate primers and Harosoy leaf cDNA as the template. The reaction (right lane) was separated on a $10 \%$ polyacrylamide gel with molecular size markers (left lane) and stained with ethidium bromide.

\section{DISCUSSION}

We have isolated a putative soybean hydroxypyruvate reductase, P42-2, that interacts with the P34 syringolide binding protein, and suggested that P42-2/P34 binding together with syringolide may specifically induce HR in Rpg4 soybeans. Surprisingly, no significant binding was detected between P42-1 and P34 although P42-1 and P42-2 share as much as $97 \%$ amino acid homology with each other. Nevertheless, secondary structure prediction for P42-1 and P42-2 revealed that there are at least four unique $\alpha$-helix structures (unpublished data). It should be addressed whether P42-1 and P42-2 are actually HPRs by in vitro enzyme assays using either enriched protein fractions (Fig. 2) or heterologously expressed proteins, though both P42-1 and P42-2 are exclusively homologous to the known plant HPRs.

HR was inhibited by co-infiltration of syringolide with glycerate or 3-phosphoglycerate but not with hydroxypyruvate or serine (Table 1). This data suggests that syringolide treatment disrupts HPR function in Rpg4 soybean leaves. One possibility is that syringolide bound to P34 inhibits P42-2 activity, preventing P42-2 binding with hydroxypyruvate, the precursor for glycerate. Similarly, binding of P42-2 with NADH, the cofactor for HPR, might be disturbed by syringolide. In any event, loss of HPR activity may lead to HR in soybean cells (Table 1). Inhibition of HPR activity should result in a shortage of glycerate (Fig. 6). The subsequent reduction in levels of 3 -phosphoglycerate may lead to disruption of the Calvin cycle. Disruption of the electron transport system in the Light reac-

$<$ P42-1> MAKPVSIEVWNPSGKYRVVSTKPMPGTRWI $<P 42-2>\quad$ MAKPVSIEVWNPSGKYRVVSTKPMPGTRWI

31 NLLV VQNDVRLEICTEKKTILSVEDIIALIGDKCDGVIGQL 31 NLLIQNDVRLEICTEKKTILSVEDIIALIGDKCDGVIGQL

71 TEDWGEQ 2 LFSTILSKAGGKAFSNMAVGYNNVDVDAANKYGV 71 TEDWGEELFSALSKAGGKAFSNMAVGYNNVDVDAANKYGV

111 AVGNTPGVLTETTAELAASL SLAAARRIVEADEFMRAGLY 111 AVGNTPGVLTETTAELAASLTLAAARRIVEADEFMRAGLY

151 DGWLPHLFVGNLLKGO TVGVIGAGRIGSAYARMMVEGFKM 151 DGWLPHLFVGNLLKGQTVGVIGAGRIGSAYARMMVEGFKM

191 NLIYYDLYYSTRLEKFITAYATFLKA $\stackrel{*}{*}$ GETPVTWKRAATM 191 NLIYYDLYQSTRLEKFVTAYAAFLKANGETPVTWKRAATM

231 DEVLQEADIISLHPVLDKTTYHLVNKERLAKMKKEAILIN 231 DEVLQEADIISLHPVLDKTTYHLVNKERLAKMKKEAILIN

271 CSRGPVIDEAALVEHLKQ̈NPMFRVGLDVFEEEPYMKPGLA 271 CSRGPVIDEAALVEHLKHNPMFRVGLDVFEEEPYMKPGLA

311 ELKNAIVVPHIASASKWTREGMATLAALNVLGKİKGYPVW 311 ELKNAIVVPHIASASKWTREGMATLAALNVLGKVKGYPVW

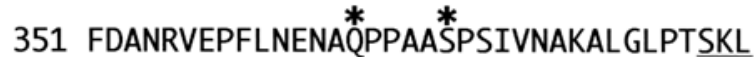 351 FDANRVEPFLNENARPPAACPSIVNAKALGLPT $\underline{\underline{S K L}}$}

Fig. 4. Amino acid alignment of P42-1 and P42-2. P42-1 and P42-2 amino acid sequences were aligned using the ClastalW command. The asterisks indicate amino acids which are not conserved between P42-1 and P42-2. The box indicates a putative NAD binding region. The underlines denote putative peroxisomal targeting signals. 
tion may generate large amounts of free radicals, and active oxygen species likely kill soybean cells. However, this model still needs more solid evidences to support it. For example, confirmation of the effects of syringolide and P34 on in vitro HPR activity of P42-2 would strengthen this HR induction model. In addition, it also remains to be addressed whether syringolide binding to $\mathrm{P} 34$ may affect P42-2 binding to $\mathrm{P} 34$, and whether substrate or co-factor binding to P42-2 can affect syringolide binding to $\mathrm{P} 34$.

Therefore, what does P42-1 do in soybean leaves? Isn't it possible that P42-1 complements P42-2 activity which is disturbed in syringolide-treated tissues? One explanation is that P42-1 and P42-2 might function differently in soybean and do not compensate for each other. All the plant HPR genes so far identified occur as single genes per haploid genomes (Greenler et al. 1989; Hayashi et al. 1996; Mano et al. 1997). This implies that one HPR gene is sufficient for normal plant growth. Therefore, P42-1 and P42-2 may have evolved from the same origin to play different roles in soybean leaves. Another possibility is that P42-1 might not have HPR activity because of the 11-amino-acid difference found between P42-1 and P42-2. HPRs to support the latter possibility.

The avrD-Rpg4 gene-for-gene complementarity is unique compared with other systems. First, syringolide is the only nonpeptide molecule known among avirulence gene-specific elicitors from viruses, bacteria, and fungi (Bonas and Lahaye 2002). Avirulence genes generally encode specific elicitors in many microorganisms but, in the case of $a v r D$, the $a v r D$ product is involved in the syringolide production pathways (Keen et al. 1990). Second, the $a v r D$ phenotype is not controlled by a type III secretion system, although many bacterial avirulence genes require this system to induce HR in plants (Leach and White 1996). In the latter cases, an avirulence gene product is injected into host cells via type III pili (Jin and He 2001) and interacts with a matching receptor. It is not yet known how syringolide is transferred into host cells to reach P34. Finally, the proteins thought to be receptors for the other avirulence elicitors share common structures, such as leucine-rich repeat, nucleotide binding site, toll/interleukin-1 receptor-like domain, leucine zipper, and protein kinase domain (Wilson and Somerville 2000). By contrast, the syringolide receptor P34 is a thiol-protease-like protein and doesn't have any of the com-

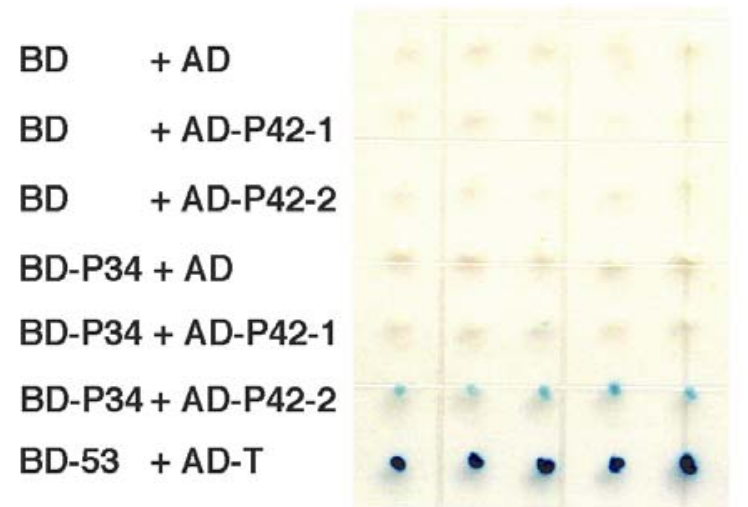

Fig. 5. Comparison of $\mathrm{P} 34$ binding ability with the two soybean hydroxypyruvate reductase isoforms. Binding of P34 with P42-1 or P42-2 was evaluated using the yeast two-hybrid system. LexA DNA binding domain (BD) alone or the BD-P34 fusion protein was coexpressed with $\mathrm{B} 42$ activation domain (AD), AD-P42-1, or AD-P42-2 protein construct in EGY48 yeast cells. Binding ability was evaluated by $\beta$-galactosidase activity, which was indicated by the intensity of blue color. Five independent transformants in each treatment were tested to eliminate possible variation in $\beta$-galactosidase activity. BD-53 $+\mathrm{AD}-\mathrm{T}$ (bottom) is the strong positive control for the yeast two-hybrid system. mon receptor features (Kalinski et al. 1990). Therefore, it is plausible that $a v r D-R p g 4$ complementarity may represent a unique elicitor-receptor system compared with other known gene-for-gene systems.

Host-specific toxins have some similarities with syringolide. Host-specific toxins are generally low-molecular-weight substances produced by phytopathogens as secondary metabolites in a gene-specific manner (Walton and Panaccione 1993). They kill host cells in advance of pathogen ingress. Some host-specific toxins also induce host defense responses classically associated with elicitors; therefore, there may not be a distinct border between toxins and elicitors (Navarre and Wolpert 1999; Walton and Panaccione 1993). Unfortunately, not much is known regarding how specific toxins kill host cells in a cultivar-specific manner. T-toxin is a host-selective toxin isolated from Cochliobolus heterostrophus race T. Ttoxin attacks the mitochondrial protein encoded by $\mathrm{T}-$ urfl3 gene in maize containing Texas male sterile cytoplasm (T-cms) and induces cell death (Dewey et al. 1988). In response to Ttoxin, T-cms mitochondria exhibit rapid swelling, uncoupling of oxidative phosphorylation, inhibition of malate-driven respiration, and leakage of small molecules such as $\mathrm{NAD}^{+}$and $\mathrm{Ca}^{2+}$. Recently, a similar event has been reported in the ACRtoxin-rough lemon system. In this case, the ACRS gene present in the host mitochondria genome confers ACR-toxin sensitivity (Ohtani et al. 2002). AAL toxins are sphinganine-analogs produced by Alternaria alternata f. sp. lycopersici and induce cell death in tomato in a unique manner. The toxins competitively inhibit de novo sphingolipid biosynthesis in tomato cells, which is salvaged by the resistance gene, Asc-1 (Brandwagt et al. 2000). Victorin, another host-specific toxin isolated from C. victoriae, is well studied and a good example to explain the similarity between syringolide and specific toxins. Victorin is a cyclized pentateptide of $814 \mathrm{Da}$ and confers an apoptotic or senescence-like cell death in oat bearing the sensitivity gene $V b$ (Navarre and Wolpert 1999). The primary

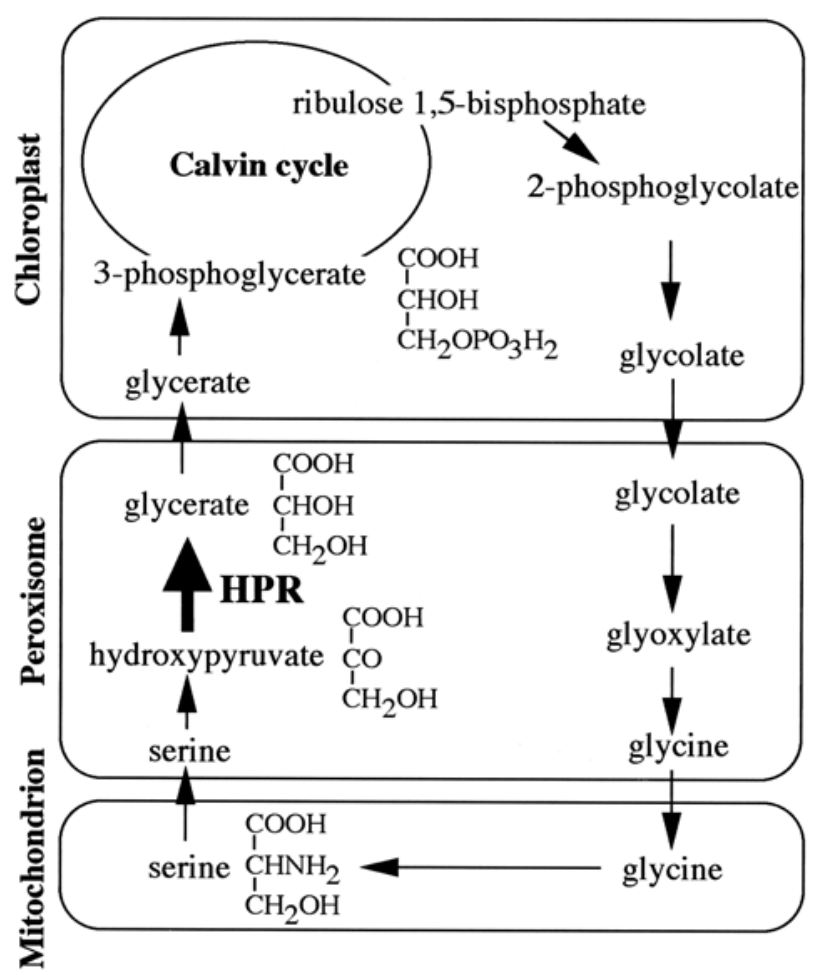

Fig. 6. A role of hydroxypyruvate reductase in a plant photosynthesis system. 
targeting site for victorin is believed to be glycine decarboxylase (GDC) in oat mitochondria, an important enzyme in the plant photorespiration system (Navarre and Wolpert 1995). However, it is not known how GDC-victorin binding mediates plant responses or how the $V b$ gene plays a role in victorin sensitivity. In our system, a role of Rpg4 in HR induction is still unknown. We identified P42-2 mRNA in soybean cv. Acme (rpg4) as well as in Harosoy by reverse-transcription, followed by sequencing (unpublished data); therefore, we expect that the P42-2 gene is not Rpg4. In the victorin-oat system, in vivo victorin-GDC binding was observed only in $V b$ oat, although in vitro binding was obtained in both $v b$ and $V b$ oat. This indicates that $V b$ may be important for victorin translocation in oat cells. Similarly, a Rpg4 product could play a role in syringolide translocation in soybean.

\section{MATERIALS AND METHODS}

\section{P34-affinity gel chromatography.}

P34 was isolated from imbibed soybean cv. Harosoy (Rgp4) seeds as described previously (Kalinski et al. 1992). Approximately $30 \mathrm{mg}$ of purified P34 was dissolved in 0.1 M MOPS, $\mathrm{pH} 7.5$, and mixed with $2 \mathrm{ml}$ of the Affi-Gel 15 gel (Bio-Rad, Hercules, CA, U.S.A.). P34 and the resin were chemically coupled according to the manufacturer's instructions. In this process, approximately $15 \mathrm{mg}$ of P34 was successfully coupled with the resin. Soluble protein fractions were prepared from 2-week-old Harosoy leaves as described previously (Ji et al. 1998) and dissolved in NP buffer $(60 \mathrm{mM}$ sodium phosphate, $\mathrm{pH}$ 7.4). The soluble fraction containing $100 \mathrm{mg}$ of protein was applied onto a column with the P34-bound Affi-Gel 15 resin, which was previously equilibrated with NP buffer. The column was washed with four-bed volumes of the same buffer and eluted with NP buffer containing a 0-to-1-M NaCl linear gradient at a flow rate of $0.2 \mathrm{ml} / \mathrm{min}$. The eluant was fractionated and used for $12 \%$ SDS-PAGE experiments to identify P42-rich fractions.

\section{P42 purification and amino acid sequences.}

P42 was further purified by ion-exchange chromatography. The P42-rich fractions were dialyzed against $30 \mathrm{mM}$ Tris- $\mathrm{HCl}$, $\mathrm{pH} 7.4$, and applied onto a DEAE BIO-GEL A column equilibrated with the same buffer. Proteins were eluted with $30 \mathrm{mM}$ Tris- $\mathrm{HCl}, \mathrm{pH} 7.4$, with a 0 -to-0.4-M NaCl linear gradient at a flow rate of $0.5 \mathrm{ml} / \mathrm{min}$. Resulting fractions were further separated by $12 \%$ SDS-PAGE and proteins were transferred onto a PVDF membrane. Proteins on the membrane were stained with Coomassie Brilliant Blue G-250 and the P42 band was

Table 1. Effects of glycerate and its analogs on hypersensitive response (HR) induced by syringolide infiltration ${ }^{\mathrm{a}}$

\begin{tabular}{ll}
\hline Substance & HR \\
\hline Control & +++ \\
$10 \mathrm{mM}$ Glycerate & ++ \\
$50 \mathrm{mM}$ Glycerate & - \\
$2 \mathrm{mM}$ 3-Phosphoglycerate & + \\
$10 \mathrm{mM}$ 3-Phosphoglycerate & - \\
$30 \mathrm{mM}$ Hydroxypyruvate & +++ \\
$100 \mathrm{mM}$ Serine & +++ \\
$100 \mathrm{mM}$ Glycerol & +++ \\
\hline
\end{tabular}

${ }^{\mathrm{a}}$ Syringolide $1(100 \mu \mathrm{g} / \mathrm{ml})$ was co-infiltrated into Harosoy leaves with the indicated substances. HR was measured at $24 \mathrm{~h}$ post infiltration. The number of plus signs $(+)$ denotes the strength of HR; $-=$ no HR was observed. No necrosis was obtained when the substances alone were infiltrated into Harosoy leaves at the concentrations indicated. Hydroxypyruvate at $30 \mathrm{mM}$ was the maximum concentration for the inhibitory test because $40 \mathrm{mM}$ hydroxypyruvate caused slight necrosis on soybean leaves. excised and sent to the UCR Genomics Institute for N-terminal amino acid sequence analysis.

\section{Isolation of P42 cDNA.}

Harosoy leaf tissues were harvested from 14-day-old plants grown at $22^{\circ} \mathrm{C}$ with a 16 -h photoperiod. Total RNA was isolated from the leaves (Sambrook et al. 1989) and poly(A) ${ }^{+}$ RNA was purified using BioMag Oligo $(\mathrm{dT})_{20}$ Kit (PerSeptive Biosystems, Hertford, U.K.). Soybean cDNA was synthesized using the SuperScript Choice System (Life Technologies, Gaithersburg, MD, U.S.A.) with oligo (dT) ${ }_{12-18}$ primer for first-strand synthesis. Resulting double-strand cDNA was used as the PCR template to amplify a P42 cDNA fragment. In this PCR, $50 \mu$ of reaction was used, which contained $0.4 \mu \mathrm{M}$ degenerated primers (PR42F, 5'-ATGGTNGARGGNTTYAARATGAA and PR42R, 5'-ACNAYDATNGCRTTYTTCATRTC, respectively), $25 \mu \mathrm{l}$ of $2 \times$ PreMix Buffer E (Epicentre Technologies, Madison, WI, U.S.A.), and 2.5 U of Taq polymerase (Epicentre Technologies). Three cycles of denaturation at $94^{\circ} \mathrm{C}$ for $40 \mathrm{~s}$, annealing at $42^{\circ} \mathrm{C}$ for $1 \mathrm{~min}$, and extension at $72^{\circ} \mathrm{C}$ for $1.5 \mathrm{~min}$ were followed by 32 cycles of denaturation at $94^{\circ} \mathrm{C}$ for $40 \mathrm{~s}$, annealing at $50^{\circ} \mathrm{C}$ for $1 \mathrm{~min}$, and extension at $72^{\circ} \mathrm{C}$ for $1.5 \mathrm{~min}$. The PCR products were separated by $10 \%$ PAGE and the major band of approximately 400 bp was recovered from the gel. This 400-bp DNA fragment was cloned into the pGEM-T easy vector (Promega, Madison, WI, U.S.A.) and sequenced to confirm predicted amino acid sequences. Full-length P42 clones were isolated from a Harosoy cDNA library. The Harosoy cDNA mentioned earlier was cloned using the Lambda ZAP II Kit (Stratagene, La Jolla, CA, U.S.A.) according to the supplier's instructions. The obtained phage library was screened by plaque hybridization (Sambrook et al. 1989) using the 400bp P42 cDNA fragment as the probe.

\section{Yeast two-hybrid assay.}

P34 interaction with P42-1 or P42-2 was evaluated using the Matchmaker Two-Hybrid System 3 (Clontec, Palo Alto, CA, U.S.A.) according to the manufacturer's instructions. The fullcoding region of P34 cDNA was introduced into pGilda bait vector so that BD-P34 fusion protein can be expressed in yeast. Similarly, P42-1 or P42-2 cDNA was introduced into $\mathrm{pB} 42 \mathrm{AD}$ prey vector to express the AD-P42-1 or AD-P42-2 fusion proteins. These bait and prey vectors were co-transformed into the EGY48 cells which carried p8op-lacZ plasmid. P34/P42 binding was evaluated by $\beta$-galactosidase activity of the co-transformant growing on the SD agar medium without Ura/His/Trp and with X-gal according to the supplier's instructions.

\section{Plant assay.}

Syringolide 1 was prepared (Midland et al. 1993) and infiltrated into Harosoy leaves (Keen et al. 1990) as described previously. Plants were grown at $22^{\circ} \mathrm{C}$ with a 16 -h photoperiod in a growth chamber and HR intensity was measured at 24 $h$ post infiltration. In the HR inhibitory tests, the chemicals were mixed with syringolide 1 solutions to give the indicated final concentrations prior to infiltration.

\section{ACKNOWLEDGMENTS}

This project was supported by a grant from the United States Department of Agriculture NRI program and support from the William and S. Sue Johnson Endowment to N. T. Keen was invaluable for the project. We acknowledge the UCR Genomics Institute and its Core Instrumentation Facility (GICIF) for the amino acid sequencing. We thank J. Becker for the critical review of the manuscript and T. Ogawa for the technical instruction for P34 isolation. 


\section{LITERATURE CITED}

Bonas, U., and Lahaye, T. 2002. Plant disease resistance triggered by pathogen-derived molecules: Refined models of specific recognition. Curr. Opin. Microbiol. 5:44-50.

Brandwagt, B. F., Mesbah, L. A., Takken, F. L., Laurent, P. L., Kneppers, T. J., Hille, J., and Nijkamp, H. J. 2000. A longevity assurance gene homolog of tomato mediates resistance to Alternaria alternata f. sp. lycopersici toxins and fumonisin B1. Proc. Natl. Acad. Sci. U.S.A. 97:4961-4966.

Dewey, R. E., Siedow, J. N., Timothy, D. H., and Levings, C. S. 1988. A 13-kilodalton maize mitochondrial protein in $E$. coli confers sensitivity to Bipolaris maydis toxin. Science 239:293-295.

Flor, H. H. 1971. Current status of the gene-for-gene concept. Annu. Rev. Phytopathol. 9:275-296.

Gould, S. J., Keller, G.-A., Hosken, N., Wilkinson, J., and Subramani, S. 1989. A conserved tripeptide sorts proteins to peroxisomes. J. Cell Biol. 108:1657-1664.

Greenler, J. M., Sloan, J. S., Schwartz, B. W., and Becker, W. M. 1989. Isolation, characterization and sequence analysis of a full-length cDNA clone encoding NADH-dependent hydroxypyruvate reductase from cucumber. Plant. Mol. Biol. 13:139-150.

Hayashi, M., Tsugeki, R., Kondo, M., Mori, H., and Nishimura, M. 1996. Pumpkin hydroxypyruvate reductases with and without a putative Cterminal signal for targeting to microbodies may be produced by alternative splicing. Plant. Mol. Biol. 30:183-189.

Ji, C., Boyd, C., Slaymaker, D., Okinaka, Y., Takeuchi, Y., Midland, S. L., Sims, J. J., Herman, E., and Keen, N. 1998. Characterization of a 34$\mathrm{kDa}$ soybean binding protein for the syringolide elicitors. Proc. Natl. Acad. Sci. U.S.A. 95:3306-3311.

Ji, C., Okinaka, Y., Takeuchi, Y., Tsurushima, T., Buzzell, R. I., Sims, J. J., Midland, S. L., Slaymaker, D., Yoshikawa, M., Yamaoka, N., and Keen, N. T. 1997. Specific binding of the syringolode elicitors to a soluble protein fraction from soybean leaves. Plant Cell 9:1425-1433.

Jin, Q., and He, S. -Y. 2001. Role of the Hrp pilus in type III protein secretion in Pseudomonas syringae. Science 294:2556-2558.

Kalinski, A., Melroy, D. L., Dwivedi, R. S., and Herman, E. M. 1992. A soybean vacuolar protein (P34) related to thiol proteases is synthesized as a glycoprotein precursor during seed maturation. J. Biol. Chem. 267:12068-12076.

Kalinski, A., Weisemann, J. M., Matthews, B. F., and Herman, E. M. 1990. Molecular cloning of a protein associated with soybean seed oil bodies that is similar to thiol proteases of the papain family. J. Biol. Chem. 265:13843-13848.

Keen, N. T., and Buzzell, R. I. 1991. New disease resistance genes in soybean against Pseudomonas syringae pv. glycinea: Evidence that one of them interacts with a bacterial elicitor. Theor. Appl. Genet. 81:133-138.
Keen, N. T., Tamaki, S., Kobayashi, D., Gerhold, D., Stayton, M., Shen, H., Gold, S., Lorang, J., Thordal-Christensen, H., Dahlbeck, D., and Staskawicz, B. 1990. Bacteria expressing avirulence gene D produce a specific elicitor of the soybean hypersensitive reaction. Mol. PlantMicrobe Interact. 3:112-121.

Kobayashi, D. Y., Tamaki, S. J., and Keen, N. T. 1990. Molecular characterization of avirulence gene D from Pseudomonas syringae pv. tomato. Mol. Plant-Microbe Interact. 3:94-102.

Leach, J. E., and White, F. F. 1996. Bacterial avirulence genes. Annu. Rev. Phytopathol. 34:153-179.

Mano, S., Hayashi, M., Kondo, M., and Nishimura, M. 1997. Hydroxypyruvate reductase with a carboxy-terminal targeting signal to microbodies is expressed in Arabidopsis. Plant Cell Physiol. 38:449-455.

Midland, S. L., Keen, N. T., Sims, J. J., Midland, M. M., Stayton, M. M., Burton, V., Smith, M. J., Mazzola, E. P., Graham, K. J., and Clardy, J. 1993. The structures of syringolides 1 and 2, novel C-glycosidic elicitors from Pseudomonas syringae pv. tomato. J. Org. Chem. 58:29402945.

Navarre, D. A., and Wolpert, T. J. 1995. Inhibition of the glycine decarboxylase multienzyme complex by the host-selective toxin victorin. Plant Cell 7:463-471

Navarre, D. A., and Wolpert, T. J. 1999. Victorin induction of an apoptotic/senescence-like response in oats. Plant Cell 11:237-249.

Ogawa, T., Bando, N., Tsuji, H., Okajima, H., Nishikawa, K., and Sasaoka, K. 1991. Investigation of the IgE-binding proteins in soybeans by immunoblotting with the sera of the soybean-sensitive patients with atopic dermatitis. J. Nutr. Sci. Vitaminol. 37:555-565.

Ogawa, T., Tsuji, H., Bando, N., Kitamura, K., Zhu, Y.-L., Hirano, H., and Nishikawa, K. 1993. Identification of the soybean allergenic protein Gly m Bd 30K, with the soybean seed 34-kDa oil-body-associated protein. Biosci. Biotechnol. Biochem. 57:1030-1033.

Ohtani, K., Yamamoto, H., and Akimitsu, K. 2002. Sensitivity to Alternaria alternata toxin in citrus because of altered mitochondrial RNA processing. Proc. Natl. Acad. Sci. U.S.A. 99:2439-2444.

Sambrook, J., Fritsch, E. F., and Maniatis, T. 1989. Molecular Cloning: A Laboratory Manual, 2nd ed. Cold Spring Harbor Laboratory Press, Cold Spring Harbor, NY.

Walton, J. D., and Panaccione, D. G. 1993. Host-selective toxins and disease specificity: Perspectives and progress. Annu. Rev. Phytopathol 31:275-303.

Wilson, I. W., and Somerville, S. C. 2000. Isolation and characterization of disease resistance genes in Arabidopsis. In: Plant-Microbe Interactions, Vol. 5. G. Stacey and N. T. Keen, eds. American Phytopathological Society Press, St. Paul, MN.

Yucel, I., Boyd, C., Debnam, Q., and Keen, N. T. 1994. Two different classes of $a v r D$ alleles occur in pathovars of Pseudomonas syringae. Mol. Plant-Microbe Interact. 7:131-139. 